\title{
Comparatively investigation of grape molasses produced by conventional and industrial techniques
}

\author{
Sinem Helvacıoğlu ${ }^{1}$, Mohammad Charehsaz ${ }^{1^{*}}$, Etil Güzelmeriç², Ebru Türköz Acar ${ }^{3}$, Erdem Yeşilada ${ }^{2}$, and Ahmet Aydın ${ }^{1}$ \\ ${ }^{1}$ Yeditepe University, Faculty of Pharmacy, Department of Toxicology, 34755, Atasehir, İstanbul, Turkey. \\ 2 Yeditepe University, Faculty of Pharmacy, Department of Pharmacognosy, 34755, Atasehir, İstanbul, Turkey. \\ ${ }^{3}$ Yeditepe University, Faculty of Pharmacy, Department of Analytical Chemistry, 34755, Ataşehir, İstanbul, Turkey.
}

ABSTRACT: In the present study, phenolic compounds compositions, antioxidant potentials and trace element contents of grape molasses produced by traditional and industrial techniques were comparatively investigated. The phenolic components (gallic acid, catechin, epigallocatechin, quercetin etc.) were evaluated using a high-performance liquid chromatographic (HPLC) method and also their total phenol and flavonoid contents were determined. Antioxidant activity of the samples were investigated by using total antioxidant capacity (TOAC), cupric reducing capacity (CUPRAC) and hydrogen peroxide scavenging activity techniques. Additionally, dietary element contents of the molasses and molasses soil samples were determined by atomic absorption and $\mathrm{X}$-ray fluorescence spectroscopy, respectively. Consequently, the concentration of phenolic compounds, total phenol contents and antioxidant activity in grape molasses produced by traditional techniques were found to be higher than that produced by industrial techniques. On the other hand, iron and copper levels in some traditionally produced samples were found to be above the limits established by the international and Turkish standards. In conclusion, production method can influence the content of grape molasses but the type of the grape, growing conditions, soil etc. should also be considered as a quality factor for the final product on market.

KEYWORDS: Vitis vinifera L., high-performance liquid chromatography (HPLC), total phenol content, antioxidant activity, dietary elements

\section{INTRODUCTION}

Fresh or processed grape (Vitis vinifera L.) is one of the widely consumed fruits in all around the world due to its delicious taste and beneficial effects on human health. Growing interest on 'French Paradox' led scientists to research its polyphenolic content such as phenolic acids, flavanols, proanthocyanidins, anthocyanins, and stilbenes (resveratrol) found in different parts of grape (seed, skin, stem, leaf etc.) and their contribution to human health [1]. Recent researches have revealed that consumption of fresh or processed grape products reduce the risk of chronic disorders such as certain types of cancer and heart diseases [2]. It inhibits the platelet aggregation and lipid peroxidation. It has also antioxidant, cholesterol-lowering, anti-inflammatory, antimicrobial, antidiabetic and hepatoprotective activities [3].

Grape molasses is a popular processed product from grape fruits with dark-colored, sweet and viscous liquid characteristics. It is produced traditionally by boiling and then condensation of the grape juice for centuries. In Turkish cuisine, grape molasses has been used as a flavor or to increase the nutritional value of desserts or to improve the taste of cookies for ancient times. It

Received: 11.08.2017/ Accepted: 17.10.2017

Corresponding Author: Mohammad Charehsaz (Muhammed Hamitoğlu)

E-mail: mohammad.saz@yeditepe.edu.tr

Phone: +902165780000

ORCID No : https://orcid.org/0000-0002-4545-0756 is considered as an important component in human nutrition and as a good source for energy intake due to its high contents of sugars (glucose, galactose), minerals and organic acids [4]. In Turkey, traditional methods are common way to obtain homemade grape molasses in villages. However, currently marketing products are obtained by modernized techniques in industrial scale. Briefly, the production process starts by squeezing grapes, and the liquid part is filtered to remove the rape. Then the filtrate is boiled until the $\mathrm{pH} 3-4$ where it becomes blurred and viscous. Finally, a special soil (named as "molasses soil") with high calcium carbonate $\left(\mathrm{CaCO}_{3}\right)$ content is added to adjust the $\mathrm{pH}$ value and to fix the turbidity [5].

Technically, boiling and condensing of grape fruits under reduced pressure to lower the boiling point in modern technique is the main difference from the traditional processing way. Consequently, processing under reduced temperature conditions would possibly prevent decomposition of grape juice components due to excessive and long-term application of heat.

Although there are many researches on the chemical composition and the biological activity of fruits, seeds, and

How to cite this article: Helvacıoğlu $S$, Charehsaz M, Güzelmeriç $E$, Türköz Acar E, Yeşilada E, Aydın A. Comparatively investigation of grape molasses produced by conventional and industrial techniques. Marmara Pharm J. 2018; 22 (1): 44-51 
leaves of grape and its products especially of wine etc., few investigations on the grape molasses have been found. The aims of the present study were to comparatively evaluate: 1) the phenolic profiles by HPLC, 2) the total phenol and flavonoid contents, 3) the antioxidant potentials, and 4) the dietary element contents of grape molasses produced by conventional and modern industrial techniques.

\section{RESULTS AND DISCUSSION}

The geographical conditions such as soil and climate are suitable for the cultivation of grapes in Turkey. Therefore, consumption of fresh grape or its processed products are popular in Turkish cuisine. This study was designed to compare some characteristics of grape molasses samples produced by conventional technique (from Canakkale, Nevsehir and Malatya) and marketed grape molasses samples produced by modern techniques.

\subsection{Phenolic and flavonoid content}

The phenolic compounds are secondary metabolites in plants with the ideal chemical structure for antioxidant properties due to their hydroxyl groups [6]. Therefore plant-based products originated from agro-industries have a great value as natural antioxidants with preventive properties against a wide range of health problems and chronic disease. Two main classes of natural antioxidants are flavonoids and phenolic acids [7]. As shown in Table 1, the TPCs of molasses samples varied from $1.70 \pm 0.13$ to $8.31 \pm 0.11 \mathrm{mg} \mathrm{GAE} / \mathrm{g}$ dry extract. The TFC contents were in the range of $0.21 \pm 0.04$ to $10.44 \pm 0.07 \mathrm{mg}$ rutin $/ g$ dry extract. The C3 had the highest TPC and TFC levels, whereas T5 had the lowest. The TPC and TFC of traditionally produced grape molasses were found to be significantly higher when compared to that of manufactured by modern techniques (Figure 1).

Table 1. Total phenolic and flavonoid contents of the molasses samples.

\begin{tabular}{lll}
\hline Samples & TPC & TFC \\
\hline C1 & $8.09 \pm 0.03$ & $8.54 \pm 0.35$ \\
C2 & $7.07 \pm 0.08$ & $6.09 \pm 0.42$ \\
C3 & $8.31 \pm 0.11$ & $10.44 \pm 0.07$ \\
M & $5.72 \pm 0.01$ & $2.86 \pm 0.18$ \\
N & $6.89 \pm 0.03$ & $3.86 \pm 0.18$ \\
T1 & $2.80 \pm 0.05$ & $0.76 \pm 0.04$ \\
T2 & $5.34 \pm 0.09$ & $3.44 \pm 0.07$ \\
T3 & $4.59 \pm 0.19$ & $1.86 \pm 0.04$ \\
T4 & $5.05 \pm 0.20$ & $3.09 \pm 0.14$ \\
T5 & $1.70 \pm 0.13$ & $0.21 \pm 0.04$ \\
\hline
\end{tabular}

Results were expressed as the mean of triplicates \pm standard deviation and as mg gallic acid and rutin equivalents in $1 \mathrm{~g}$ of samples for TPC and TFC, respectively. $\mathrm{C} 1, \mathrm{C} 2, \mathrm{C} 3, \mathrm{M}$ and $\mathrm{N}$ are samples produced by traditional technique and $\mathrm{T} 1-\mathrm{T} 5$ represent the samples produced by modern industrial technique. TPC: Total Phenolic Content, TFC: Total Flavonoid Content.

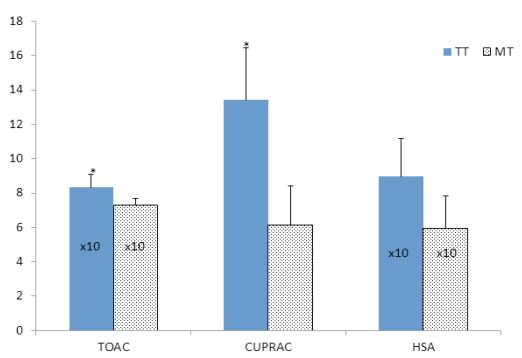

Figure 1. The comparison of TPC (total phenolic content) and TFC (total flavonoid content) of molasses samples produced by traditional (TT) $(\mathrm{n}=5)$ and modern industrial techniques (MT) $(n=5)$. Results were expressed as the mean of triplicates \pm SD. ${ }^{\star} \mathrm{p}<0.05$ compared to MT. Mann-Whitney U test was used to compare to independent groups medians. For TPC analysis median was 7.07 (5.72-8.31) for traditional samples and 4.59 (1.70-5.34) for modern industrial samples. For TFC analysis median was $6.09(2.86-10.44)$ for traditional samples and 1.86 (0.21-3.44) for modern samples.

In addition to the determination of TPC, the phenolic profile of different molasses samples including gallic acid, catechin, chlorogenic acid, epigallocatechin, caffeic acid, p-coumaric acid, ferrulic acid, rutin and quercetin was investigated by HPLC-DAD technique in this study.

The results of HPLC analysis of phenolic profile were given in Table 2. The identity of the standards in test solutions of molasses samples were confirmed by comparing the retention time (Rt) with reference mixture solution. In accordance with the results of TPC test, molasses samples produced by traditional and modern techniques demonstrated a different phenolic component profile. Among the studied reference standards the major phenolic components in traditionally produced samples were determined to be gallic acid, catechin, chlorogenic acid, caffeic acid, p-coumaric acid, ferulic acid, and rutin, whereas in commercial samples produced by modernized techniques only gallic acid, ferulic acid and rutin were found as main components. 
Table 2. Phenolic profiles of the molasses samples produced by traditional and modern industrial techniques.

\begin{tabular}{llllllll}
\hline & \multicolumn{7}{c}{ Phenolic contents $(\boldsymbol{\mu g} / \mathbf{g}$ extract) } \\
\hline Samples & $\mathbf{1}$ & $\mathbf{2}$ & $\mathbf{3}$ & $\mathbf{4}$ & $\mathbf{5}$ & $\mathbf{6}$ & $\mathbf{7}$ \\
\hline C1 & ND & ND & ND & $27.83 \pm 4.18$ & $6.11 \pm 0.31$ & $2.03 \pm 0.28$ & ND \\
C2 & $3.70 \pm 0.02$ & ND & ND & ND & $1.90 \pm 0.01$ & $0.24 \pm 0.01$ & $1.25 \pm 0.01$ \\
C3 & $10.42 \pm 0.02$ & ND & ND & $6.42 \pm 0.01$ & ND & $1.88 \pm 0.02$ & $6.78 \pm 0.01$ \\
M & ND & $2.73 \pm 0.70$ & $12.29 \pm 0.01$ & ND & ND & $2.21 \pm 0.01$ & $62.97 \pm 0.27$ \\
N & ND & ND & ND & $28.08 \pm 4.11$ & $5.06 \pm 0.10$ & ND & ND \\
T1 & $3.45 \pm 0.01$ & ND & ND & ND & ND & ND & ND \\
T2 & $5.15 \pm 0.01$ & ND & ND & ND & ND & $2.46 \pm 0.01$ & $4.69 \pm 0.01$ \\
T3 & $1.62 \pm 0.03$ & ND & ND & ND & ND & ND & ND \\
T4 & ND & ND & ND & ND & ND & ND & ND \\
T5 & ND & ND & ND & ND & ND & ND & ND \\
\hline
\end{tabular}

1: gallic acid, 2: catechin, 3: chlorogenic acid, 4: caffeic acid, 5: para-coumaric acid, 6: ferulic acid, 7: rutin; Grape molasses produced by traditional technique: C1, C2, C3, M and N ; Modern traditional technique: T1-T5; ND: non-detected.

It is well known that the chemical structure of phenolic compounds are susceptible to various factors, including enzymatic reactions, $\mathrm{pH}$ changes, matrix effects, temperature, etc [8]. Especially, heating condition thwat is necessary for preparation of molasses can change the structure of phenolic compounds. Some previous studies reported that TPC and subsequent antioxidant activity declined in agricultural products with increasing temperature [9-12]. On the other hand, the TPC of grape seed was found to be significantly higher when heated at $150^{\circ} \mathrm{C}$ for 40 minutes compared to the unheated seeds [13]. Pinelo et al., [14] evaluated the antioxidant capacity of grape extract and its relationship between thermal treatments. The antioxidant activity of the extracted grape was strongly affected by heat. The antioxidant activity was found to be higher as the storage temperature was increased. This increase in the antioxidant activity of the grape extract explained on the basis of the formation of oligomers from free polyphenols.

In another study, effects of heating on antioxidant activity of grape seeds has been investigated [15]. The study reported that the contents of gallocatechin, gallate and caffeine in grape seed extract significantly increased by heat treatment and thus increased the antioxidant activity. This study has shown that simple heat treatment possibly converted insoluble phenolic compounds to soluble phenolic compounds. In accordance with the results of previous studies, the phenolic content of the molasses samples produced conventionally using high temperature was found to be higher than the samples manufactured under vacuum condition with lower temperature in present study. However, it should be noted that other factors such as growing conditions of grape, the amount of used grape, environmental factors, genotype of grape, soil type, post-harvest treatments may also alter the phenolic compounds in molasses.

\subsection{Assessment of in vitro antioxidant potential}

\subsubsection{Total antioxidant capacity}

TOAC assay is commonly used as an antioxidant parameter based on the reduction of Mo (VI) to Mo (V) and subsequent formation of a green phosphate/Mo (V) complex at low $\mathrm{pH}$ [8]. The results were given in Table 3 . The total antioxidant capacities of traditionally produced grape molasses were found to be significantly higher when compared to that of manufactured by modern industrial techniques (Figure 2).

Table 3. Total antioxidant, cupric ion reducing antioxidant capacities and $\mathrm{H}_{2} \mathrm{O}_{2}$ scavenging activity of the molasses samples produced by traditional and modern industrial techniques.

\begin{tabular}{lccc}
\hline Samples & TOAC & CUPRAC & HSA \\
\hline C1 & $81.64 \pm 1.02$ & $14.69 \pm 0.17$ & $95.46 \pm 5.89$ \\
C2 & $78.55 \pm 4.50$ & $12.04 \pm 1.02$ & $93.58 \pm 6.78$ \\
C3 & $80.30 \pm 2.32$ & $17.68 \pm 0.36$ & $121.50 \pm 12.67$ \\
M & $79.38 \pm 3.05$ & $9.57 \pm 0.27$ & $68.38 \pm 4.71$ \\
N & $96.64 \pm 2.18$ & $13.03 \pm 0.05$ & $69.42 \pm 2.65$ \\
T1 & $68.18 \pm 1.74$ & $6.53 \pm 0.38$ & $48.79 \pm 1.18$ \\
T2 & $71.16 \pm 2.18$ & $7.88 \pm 0.47$ & $77.75 \pm 0.88$ \\
T3 & $76.09 \pm 2.47$ & $5.94 \pm 0.02$ & $70.42 \pm 2.06$ \\
T4 & $74.24 \pm 1.02$ & $7.96 \pm 0.38$ & $69.83 \pm 0.29$ \\
T5 & $76.29 \pm 1.60$ & $2.34 \pm 0.44$ & $32.33 \pm 3.83$ \\
\hline
\end{tabular}

Results were expressed as the mean of triplicates \pm standard deviation and as $\mathrm{mg}$ ascorbic equivalents (AAE) in $1 \mathrm{~g}$ sample. $\mathrm{C} 1, \mathrm{C} 2, \mathrm{C} 3, \mathrm{M}$ and $\mathrm{N}$ are samples produced by traditional technique and samples encoded as T1-T5 represent modern industrial technique. TOAC: total antioxidant capacity, CUPRAC: cupric reducing antioxidant capacity. HSA: hydrogen peroxide scavenging activity. 


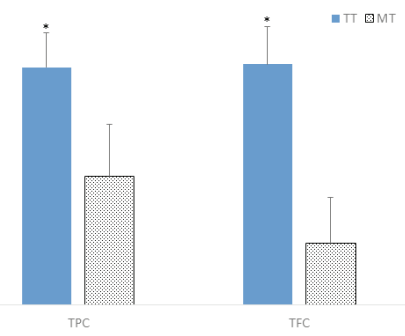

Figure 2. The comparison of TOAC (Total antioxidant capacity), CUPRAC (Cupric ion reducing antioxidant capacity) and HSA (hydrogen peroxide scavenging activity) of molasses samples produced by traditional (TT) $(n=5)$ and modern industrial techniques (MT) $(n=5)$. Results were expressed as the mean of triplicates \pm SD. ${ }^{*} \mathrm{p}<0.05$ compared to MT. Mann-Whitney $U$ test was used to compare to independent groups medians. For TOAC analysis median was 80.30 (78.55-96.64) for traditional samples and 74.24 (68.18-76.29) for modern industrial samples. For CUPRAC analysis median was 13.03 (5.97-17.68) for traditional samples and 6.53 (2.34-7.96) for modern industrial samples. For HSA analysis median was 93.58 (68.38-121.50) for traditional samples and $69.42(32.33-77.75)$ for modern industrial samples.

\subsubsection{Cupric ion reducing antioxidant capacity}

CUPRAC test is a method relying on metal ion reducing, and widely used as an antioxidant capacity index particularly for dietary polyphenolics. The reduction of the cupric ion, which takes part in the formation of free radicals, gives information about the antioxidant potential of the studied samples [8]. The results of CUPRAC assay were given in Table 3 . In accordance with the results of TOAC test, CUPRAC activity found to be significantly higher in grape molasses samples produced by traditionally technique compared to that of samples manufactured by modern industrial techniques (Figure 2).

\subsection{3. $\mathrm{H}_{2} \mathrm{O}_{2}$ scavenging activity}

$\mathrm{H}_{2} \mathrm{O}_{2}$ itself is not very reactive, but it is considered among the reactive oxygen species since it may give rise to hydroxyl radical in the cells. Thereby, the scavenging of $\mathrm{H}_{2} \mathrm{O}_{2}$ is crucial for antioxidant defense in cell or food systems [8]. $\mathrm{H}_{2} \mathrm{O}_{2}$ scavenging activity of different molasses samples

was presented in Table 3. In accordance with the results of previous tests, although the statistically significance was not achieved, the highest activity was shown in samples produced by conventional technique (Figure 2).

Overall, the antioxidant capacity of molasses samples correlates well with their antioxidant TPC and TFC contents. Similar to the TPC and TFC results, the total antioxidant, cupric ion reducing antioxidant and $\mathrm{H}_{2} \mathrm{O}_{2}$ scavenging activity of traditionally produced grape molasses were found to be higher when compared to that of samples manufactured by modern industrial technique under reduced temperature. It was stated that, pro-oxidant and antioxidant molecules may be formed depending on the degree of thermal treatment applied. During heat treatment antioxidants, naturally found in food, can be degraded and new components with antioxidant activity can be formed [16]. Increased antioxidant activity in traditionally produced samples may possibly be explicated by the grade and duration of the applied temperature.

\subsection{Dietary element contents in molasses and molasses soil samples}

Dietary elements occur in living tissues in small amounts and they are called micronutrients. $\mathrm{Fe}, \mathrm{Cu}, \mathrm{Mn}, \mathrm{Zn}$ and $\mathrm{Mg}$ are essential elements which involved in biochemical reactions in the body. Fe is significant part of tissue and blood in human bodies. Fe deficiency is the most common nutritional deficiency worldwide and anemia is the major manifestation of Fe deficiency.

$\mathrm{Cu}$ is an essential component of several enzymes such as cytochrome c-oxidase and lysyl oxidase. Cytochrome c-oxidase is gaining importance because it catalyzes a key reaction in energy metabolism and its deficiency results in severe pathology in human. Lysyl oxidase initiates the covalent crosslinkage between elastin and collagen, thereby it is important for the formation and repair of extracellular matrix.

$\mathrm{Mn}$ is present in the human body in small amounts and its deficiency has been associated with impaired growth, skeletal abnormalities and disturbed reproductive functions.

$\mathrm{Zn}$ is an essential element of a large number metalloenzymes participating in a wide variety of metabolic processes. It is also essential for healthy immune system, normal growth and development during pregnancy, childhood and adolescence. Furthermore, $\mathrm{Zn}$ and $\mathrm{Cu}$ are key components of $\mathrm{Cu} / \mathrm{Zn}$ superoxide dismutase enzyme present in most cells and protects from oxygen toxicity by scavenging superoxide radicals.

Another essential dietary element, $\mathrm{Mg}$, serves as a cofactor of numerous enzyme such as those have key role in the glycolytic cycle. It is known that Mg deficiency in human body leads to neuro-muscular irritability, frank tetany, inflammatory syndrome and even convulsions [17]. 
In this study, different element values were found in investigated molasses samples. The factors such as element content and chemical composition of soils may be the reason of this observation.

The concentrations of $\mathrm{Fe}, \mathrm{Cu}, \mathrm{Mn}, \mathrm{Zn}$ and $\mathrm{Mg}$ were observed to be within the ranges of $0.39-1.87 ; 0.01-0.29 ; 0.21-1.31$; $0.25-0.86$ and $38.78-108.94$ in samples produced by modern industrial technique and $1.15-8.4 ; 0.20-2.18 ; 0.44-1.24 ; 0.13$ 0.63 and $37.71-80.89 \mathrm{mg} / 100 \mathrm{~g}$ for traditionally produced samples, respectively. The intake of $100 \mathrm{~g}$ molasses samples produced by modern industrial technique was also compared to the recommended daily allowances (RDAs) of these elements (Table 4). During the production of grape molasses, approximately $80 \%$ of its water content is evaporated and condensed product is clarified and filtered. Hence it is expected that these steps in processing the molasses resulted in loss of some elements, particularly during the filtering step. However, our results demonstrated that the final product still contains considerable amount of essential dietary elements and are considered a good source for $\mathrm{Mn}, \mathrm{Mg}, \mathrm{Cu}$ and $\mathrm{Fe}$.

Table 4. Comparison of the "Recommended Dietary Allowance" values for dietary elements through consumption of $100 \mathrm{~g}$ of molasses produced by modern industrial technique.

\begin{tabular}{|l|l|l|l|l|l|}
\hline Element & $\begin{array}{l}\mathrm{RDA}^{*} \\
(\mathrm{mg} / \text { day })\end{array}$ & $\begin{array}{l}\text { Average content }(\mathrm{mg}) \text { in } \\
100 \mathrm{~g} \text { of sample }\end{array}$ & \multicolumn{2}{l|}{ of RDA } \\
& $\begin{array}{l}\text { Male } \\
(19-50 \text { years })\end{array}$ & $\begin{array}{l}\text { Female } \\
(19-50 \text { years })\end{array}$ & $\begin{array}{l}\text { Male } \\
(19-50 \text { years })\end{array}$ & $\begin{array}{l}\text { Female } \\
(19-50 \text { years })\end{array}$ \\
\hline $\mathrm{Fe}$ & 6 & 8.1 & $\begin{array}{l}1.11 \pm 0.54 \\
0.39-1.87^{* *}\end{array}$ & 18.50 & 13.70 \\
\hline $\mathrm{Cu}$ & 0.7 & 0.7 & $\begin{array}{l}0.17 \pm 0.10 \\
0.01-0.29^{* *}\end{array}$ & 24.29 & 24.29 \\
\hline $\mathrm{Mn}$ & 2.3 & 1.8 & $\begin{array}{l}0.90 \pm 0.58 \\
0.21-1.31^{* *}\end{array}$ & 39.13 & 50.00 \\
\hline $\mathrm{Zn}$ & 9.4 & 6.8 & $\begin{array}{l}0.51 \pm 0.23 \\
0.25-0.86^{* *}\end{array}$ & 5.43 & 7.50 \\
\hline $\mathrm{Mg}$ & $330-350$ & $255-265$ & $\begin{array}{l}80.69 \pm 26.48 \\
38.78-108.94^{* *}\end{array}$ & $24.45-23.05$ & $31.64-30.45$ \\
\hline
\end{tabular}

* The daily intake of elements was evaluated in view of American recommended dietary intakes (RDA) [19].

** These values represent the range of dietary element contents in $100 \mathrm{~g}$ of molasses samples produced by modern industrial technique $(\mathrm{n}=5)$

For traditionally produced molasses, the comparison of trace element contents with the recommended dietary allowances (RDA) were not included in Table 4, because some samples contained abnormally high amount of $\mathrm{Fe}$ and $\mathrm{Cu}$. As illustrated in Figure 3, the Fe levels in $\mathrm{C} 3$ and $\mathrm{N}$ samples were found to be 85.84 and $36.95 \mathrm{mg} / \mathrm{kg}$, respectively. The concentration of $\mathrm{Cu}$ in $\mathrm{C} 2, \mathrm{C} 3$ and $\mathrm{N}$ samples were 21.88 , 12.72 and $6.70 \mathrm{mg} / \mathrm{kg}$, respectively. These levels were found to be above the limits established by the Turkish standards for Fe $(25 \mathrm{mg} / \mathrm{kg})$ and $\mathrm{Cu}(5 \mathrm{mg} / \mathrm{kg})$ contents in grape molasses samples [18] as well as the suggested daily intake levels by the international authorities. It is important to note that even the trace elements are essential for human body functions their high levels may give rise to some health risks.

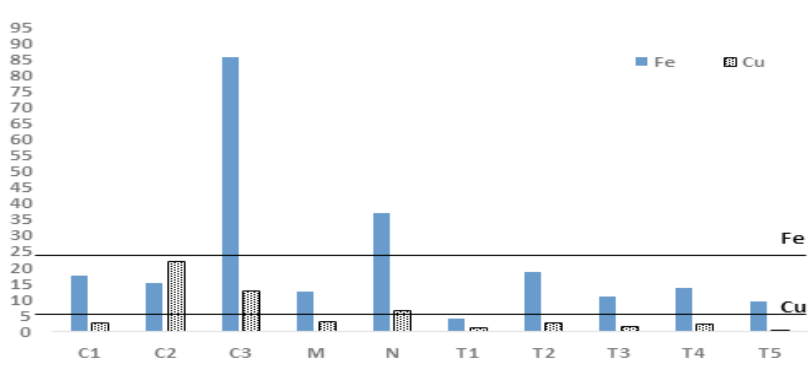

Figure 3. Fe and $\mathrm{Cu}$ contents of molasses samples produced by traditional $(\mathrm{n}=5)$ and modern industrial techniques $(\mathrm{n}=5) . \mathrm{C} 1, \mathrm{C} 2, \mathrm{C} 3, \mathrm{M}$ and $\mathrm{N}$ are samples produced by traditional technique and samples encoded as T1-T5 represent modern industrial technique.

Consumption of $100 \mathrm{~g} \mathrm{C} 2$ or C3 samples contributes 300 and 177 percent of the daily $\mathrm{Cu}$ requirement. Considering 
the additional daily $\mathrm{Cu}$ intake from other food and beverage sources, this will be resulted in Cu overload in the body. Fe and $\mathrm{Cu}$ contents of molasses soil samples from Canakkale province were also determined in this study. The $\mathrm{Cu}$ levels were 0.010 $\pm 0.001 ; 0.008 \pm 0.001$ and $0.009 \pm 0.002$ for soil samples used in production of $\mathrm{C} 1, \mathrm{C} 2$ and $\mathrm{C} 3$ molasses, respectively. The Fe levels of same soil samples were $2.941 \pm 0.177 ; 1.805 \pm 0.013$ and $3.535 \pm 0.144$. Our results suggest that the higher amount of Fe in traditionally produced molasses may be most probably due to the addition of molasses soil to balance the $\mathrm{pH}$ value during molasses production. While the high levels of $\mathrm{Cu}$ in traditional samples may be expounded with frequent use of copper cauldrons by the local people due to its high thermal conductivity during the molasses production.

\section{CONCUSION}

Use of vacuum under controlled conditions to reduce the boiling point is the main difference between the conventional and modernizes preparation techniques. If we consider that the valuable ingredients in grape juice such as phenolics may exposed to structural decomposition during the boiling process, apparently, production of grape molasses via modern industrial techniques might be expected to be healthier. However, higher antioxidant potentials have been determined in grape molasses produced traditionally comparing to the modern industrial techniques. Thus can be concluded that production process is not only the qualification parameter in final products. The type of cultivar, growing conditions, soil composition etc. should also be considered in evaluation of the final product. On the other hand, excessive Fe and $\mathrm{Cu}$ contents in some traditionally produced samples are a concerning point for public health and the national authority needs to increase its supervision on the traditional production of molasses.

\section{MATERIALS AND METHODS}

\subsection{Chemicals}

HPLC grade methanol was obtained from Sigma-Aldrich (St. Louis, MO, USA). The other solvents were of analytical grade. O-phosphoric acid and ammonium acetate were from Merck (Darmstadt, Germany). Neocuproine was from Santa Cruz (Dallas, USA). The ultrapure water was obtained from Millipore, Simplicity UV (Darmstadt, Germany). All other chemicals were purchased from Sigma-Aldrich (Steinheim, Germany).

\subsection{Materials and sample preparation}

Traditionally produced grape molasses were obtained from Canakkale (located in the northwestern part of Turkey),
Nevsehir (central) and Malatya (located in the eastern part of the country) provinces of Turkey. The three products obtained from Canakkale encoded as C1-3, a product from Nevsehir encoded as $\mathrm{N}$ and a product from Malatya coded as $\mathrm{M}$.

Grape molasses samples, which are produced via modern technique, were purchased from local markets in Istanbul (Turkey) and coded as T1, T2, T3, T4 and T5.

Aliquots $(10 \mathrm{~mL})$ of grape molasses samples were lyophilized weight. The yields were (in gram): 9.88 (C1), 9.44 (C2), 9.23 (C3), $18.03(\mathrm{~N}), 9.89(\mathrm{M}), 11.92$ (T1), 11.02 (T2), 9.48 (T3), 10.41 (T4) and 12.47 (T5).

\subsection{Determination of total phenolic and flavonoid content}

For the measurement of the total phenolic content (TPC), Folin-Ciocalteau reagent and sodium carbonate (7.5\%) were added to $0.5 \mathrm{~mL}$ of the test samples and incubated for $90 \mathrm{~min}$ at room temperature. After the incubation period, samples were centrifuged at $2000 \mathrm{rpm}$ for $10 \mathrm{~min}$ and blue color was measured at $725 \mathrm{~nm}$ using spectrophotometer (Thermo, Evolution 300). The results were expressed as gallic acid equivalents GAE/g of the material [20].

Total flavonoid contents (TFC) of the extracts were measured using the method described by Samatha et al. [21]. Briefly, 0.5 $\mathrm{ml}$ of samples were taken in different test tubes and $2 \mathrm{~mL}$ of distilled water was added followed by the addition of $0.15 \mathrm{~mL}$ of sodium nitrite $\left(5 \% \mathrm{NaNO}_{2}, \mathrm{w} / \mathrm{v}\right)$. After $6 \mathrm{~min}$ of incubation in room temperature, $0.15 \mathrm{~mL}$ of $\mathrm{AlCl}_{3}(10 \% \mathrm{w} / \mathrm{v})$ was added followed by the addition of $2 \mathrm{ml}$ of sodium hydroxide $(\mathrm{NaOH}$, $4 \% \mathrm{w} / \mathrm{v}$ ) and volume was made up to the $5 \mathrm{~mL}$ with distilled water. After $15 \mathrm{~min}$ of incubation, the pink color absorbance was measured at $510 \mathrm{~nm}$. The TFC was expressed in mg of rutin equivalents (RE) per gram of extract.

\subsection{Determination of phenolic profile by HPLC}

Each lyophilized sample ( $2 \mathrm{~g}$ ) was dissolved in $10 \mathrm{~mL}$ of water and extracted with $10 \mathrm{~mL}$ of ethyl acetate in three times. Then, combined ethyl acetate fraction was evaporated to dryness using rotary vapor and lyophilized. Each test solution was prepared for HPLC analysis in the concentration of $1 \mathrm{mg}$ lyophilized extract in $1 \mathrm{~mL}$ of mobile phase mixture $(1: 1, \mathrm{v} / \mathrm{v})$ and filtered through $0.45 \mu \mathrm{m}$ RC-membrane filter (Sartorius stedim biotech) prior the analysis.

Stock solutions of gallic acid, catechin, epigallocatechin, quercetin, chlorogenic acid, ferulic acid, p-coumaric acid, rutin and caffeic acid $(1 \mathrm{mg} / \mathrm{mL})$ were dissolved in methanol and each was further diluted with methanol to prepare standard mixtures (1-100 $\mu \mathrm{g} / \mathrm{mL})$ for HPLC analysis.

HPLC-DAD analysis was performed on an Agilent 1200 HPLC (Germany) system which connected with a diode array detector (DAD). Samples were injected into a Zorbax Eclipse 
XDB-C18, $150 \times 4.6 \mathrm{~mm}, 3.5 \mu \mathrm{m}$ particle sized analytical column. The flow rate was $1 \mathrm{~mL} / \mathrm{min}$ and the column temperature was set at $25^{\circ} \mathrm{C}$. Separation of the phenols was achieved by using gradient elution system. For this purpose, two different mobile phases were used. Mobile phase A was $10 \mathrm{mM}$ phosphoric acid solution and mobile phase B was methanol. Gradient elution time operation system is shown in Table 5.

Table 5. Gradient elution parameters in HPLC analysis.

\begin{tabular}{ll}
\hline Time & Mobile Phase B (\%) \\
\hline 0 & 0 \\
15 & 60 \\
20 & 80 \\
22 & 100 \\
25 & 0 \\
30 & 0 \\
\hline
\end{tabular}

To monitor the analytes, different wavelength values were used. These values were selected according to UV spectrum of each material observed in the HPLC-DAD system. p-coumaric acid was monitored at $306 \mathrm{~nm}$, while gallic acid, catechin, epigallocatechin, rutin, quercetin were monitored at $214 \mathrm{~nm}$ and chlorogenic acid, caffeic acid, and ferrulic acid at $333 \mathrm{~nm}$.

\subsection{Assessment of in vitro antioxidant potential}

\subsubsection{Total antioxidant capacity (TOAC) measurement}

The assessment of total antioxidant capacities was performed by using phosphomolybdenum method [22]. Briefly, 300 $\mu \mathrm{L}$ of samples were mixed with $3 \mathrm{~mL}$ of reagent solution consisting of sodium phosphate monobasic, ammonium molybdate and sulfuric acid. After 90 minutes of incubation at $95^{\circ} \mathrm{C}$, the absorbance was recorded at $695 \mathrm{~nm}$. The total antioxidant capacities were expressed as $\mathrm{mg}$ ascorbic acid equivalent (AAE).

\subsubsection{Cupric reducing antioxidant capacity (CUPRAC) measurement}

For the evaluation of the cupric ion reducing capacities of the samples, equal volumes of $\mathrm{CuSO}_{4}$, neocuproine, and ammonium acetate buffer ( $\mathrm{pH}$ 7.0) solutions were mixed together. Then, $0.5 \mathrm{~mL}$ of sample solutions was added and the total volume was completed to $4.1 \mathrm{~mL}$ with water. The samples were incubated for $1 \mathrm{~h}$ at room temperature and the absorbance was recorded at $450 \mathrm{~nm}$. The results were expressed as mg ascorbic acid equivalents (AAE) [23].

\subsubsection{Hydrogen peroxide scavenging activity measurement}

Hydrogen peroxide $\left(\mathrm{H}_{2} \mathrm{O}_{2}\right)$ scavenging potential of the molasses samples was determined using the method described by Jayaprakasha et al. [24]. A solution of $20 \mathrm{mM}$ hydrogen peroxide was prepared in phosphate buffer $(\mathrm{pH}$ 7.4) and $1 \mathrm{~mL}$ of extracts $(10 \mathrm{mg} / \mathrm{mL}$ ) were added to $2 \mathrm{~mL}$ of this solution. After 10 minutes the absorbance was measured at $230 \mathrm{~nm}$ against a blank solution that contained hydrogen peroxide solution without the extract. The results were expressed as mg ascorbic acid equivalent (AAE) per g dry material.

\subsection{Trace element level measurement of samples}

For digestion of samples, accurately weighed $1 \mathrm{~g}$ of them was dissolved with $6 \mathrm{~mL}$ of nitric acid (65\%) and $2 \mathrm{~mL}$ of hydrogen peroxide (30\%). Then the samples were dried by increasing the temperature from $40-50{ }^{\circ} \mathrm{C}$ to $140{ }^{\circ} \mathrm{C}$, using a water bath heater (GFL, Germany). After dryness, the residue was diluted to $10 \mathrm{~mL}$ with de-ionized water [25].

Iron $(\mathrm{Fe})$, copper $(\mathrm{Cu})$, manganese $(\mathrm{Mn})$, zinc $(\mathrm{Zn})$ and magnesium $(\mathrm{Mg})$ determination in digested samples was done by flame atomic absorption spectrometry (Analytic Jena, Zeenit 700, Germany). The calibration curve was plotted with standard solutions of $\mathrm{Cu}(0.35-2.80 \mu \mathrm{g} / \mathrm{mL})$, Fe $(0.75-6.00 \mu \mathrm{g} / \mathrm{mL}), \mathrm{Mn}(0.3-2.4 \mu \mathrm{g} / \mathrm{mL}), \mathrm{Zn}(0.125-$ $1.00 \mu \mathrm{g} / \mathrm{mL})$ and $\mathrm{Mg}(0.05-0.2 \mu \mathrm{g} / \mathrm{mL})$. Suitable dilutions were made from digested samples with triply distilled water. The manufacturer's application notes were used for element measurements checking validation parameters.

\subsection{Element level measurement of the molasses soil}

Fe and $\mathrm{Cu}$ contents of molasses soils which are used to balance the $\mathrm{pH}$ value and to fix the turbidity during traditionally production of molasses were analyzed by X-ray fluorescence spectroscopy (XRF). Briefly, the soil sample was ground in a mill (Pulverisette7, premium line, Germany) at 350 RPM for $4 \mathrm{~min}$. The ground material was mixed with cellulose microcrystalline (Alfa Aesar, Germany) and pelleted under a pressure of $2 \mathrm{t} / \mathrm{cm}^{2}$, then a direct XRF (Zetium, PANalytical, Netherlands) analysis was carried out.

\subsection{Statistical analysis}

The quantitative results of HPLC analyses of each sample test solution applied in triplicate and results were expressed as mean \pm standard deviation (SD). For descriptive statistic mean \pm SD and median range were used. Mann-Whitney $U$ test was used to compare to independent groups medians. These treatments were carried out by using SPSS Data Editor (version 20.0). 


\section{Acknowledgements}

Authors are grateful to the Scientific and Technological Research Council of Turkey (TÜBİTAK) for supporting of this study (215S651).

\section{Authorship statement}

Author contributions: Concept - M.CH., S.H.; Design S.H., M.CH.; Supervision - E.Y., A.A; Resource - M.CH., E.Y., A.A; Materials - M.CH., E.Y., A.A. ; Data Collection and/or Processing - S.H., E.G., E.T.A.; Analysis and/or Interpretation - S.H., E.G., E.T.A, M.CH.; Literature Search - S.H., E.T.A, M.CH.; Writing - S.H., M.CH., E.T.A, E.G.; Critical Reviews - S.H., M.CH., E.G., E.T.A., E.Y., A.A.

\section{Conflict of interest}

Authors declare no conflict of interest.

\section{REFERENCES}

[1] Xia EQ, Deng GF, Guo YJ, Li HB. Biological activities of polyphenols from grapes. Int J Mol Sci. 2010; 11:622-646.

[2] Yang Y, Xiao YY. Grape phytochemicals and associated health benefits. Crit Rev Food Sci Nutr. 2013; 53:1202-1225.

[3] Nassiri-Asl M, Hosseinzadeh H. Review of the pharmacological effects of Vitis vinifera (Grape) and its bioactive constituents. An Update Phytother Res. 2016; 30:1392-1403.

[4] Özcan M, Alpar Ş, Juhami-Al F. The effect of boiling on qualitative properties of grape juice produced by the traditional method. J Food Sci Technol. 2015; 52:5546-5556.

[5] Atabey E. Pekmez ve Pekmez Toprağı. Popüler Bilim Derg. 2011; 19:38-43.

[6] Rice-Evans C, Miller NJ, Paganga G.Antioxidant properties of phenolic. Trends Plant Sci. 1997; 2:152-159.

[7] Keser S, Celik S, Turkoglu S. Total phenolic contents and freeradical scavenging activities of grape (Vitis vinifera L.) and grape products. Int J Food Sci Nutr. 2013; 64:210-216.

[8] Celep E, Charehsaz M, Akyüz S, Türköz-Acar E, Yesilada E. Effect of in vitro gastrointestinal digestion on the bioavailability of phenolic components and the antioxidant potentials of some Turkish fruit wines. Food Res Int. 2015; 78:209-215.

[9] Chen YT, Lin KW. Effects of heating temperature on the total phenolic compound, antioxidative ability and the stability of dioscorin of various yam cultivars. Food Chem. 2007; 101:955-963.

[10] Gawlik-Dziki U. Effect of hydrothermal treatment on the antioxidant properties of broccoli (Brassica oleracea var. botrytis italica) florets. Food Chem. 2008; 109:393-401.

[11] Podsedek A, Sosnowska D, Redzynia M, Koziotkiewicz M. Effect of domestic cooking on the red cabbage hydrophilic antioxidants. Int J Food Sci Technol. 2008; 43:1770-1777.
[12] Wolosiak R, Worobiej E, Piecyk M, Druzynska B, Nowak D, Lewicki PP. Activities of amine and phenolic antioxidants and their changes in broad beans (Vicia faba) after freezing and steam cooking. Int J Food Sci Technol. 2009; 45:29-37.

[13] Ross CF, Hoye C, Fernandez-plotka VC. Influence of heating on the polyphenolic content and antioxidant activity of grape seed flour. J Food Sci. 2011; 76:884-890.

[14] Pinelo M, Rubilar M, Sinerio J, Nunez MJ. A thermal treatment to increase the antioxidant capacity of natural phenols: Catechin, resveratrol and grape extract cases. Eur Food Res Technol. 2005; 221:284-290.

[15] Kim SY, Jeong SM, Park WP, Nam KC, Ahna DU, Lee SC. Effect of heating conditions of grape seeds on the antioxidant activity of grape seed extract. Food Chem. 2006;97:472-479.

[16] Calligaris S, Manzocco L, Anese M, Nicoli MC. Effect of heattreatment on the antioxidant and pro-oxidant activity of milk. Int Dairy J. 2004;14:421-427.

[17] Jiu J, Goyer RA, Waalkes MP. Toxic effects of metals. In: The Casarett \& Doull's Toxicology the basic science of poisons, (ed. C. D. Klaassen). Mc Graw Hill., New York,2008, pp. 931-979.

[18] Türk Gıda Kodeksi Üzüm Pekmezi Tebliği, TEBLİĞ NO: 2007/27, 2007, http://www.resmigazete.gov.tr/ eskiler/2007/06/20070615-6.htm (accessed December 20, 2016).

[19] American recommendations, Food and Nutrition Board, Institute of Medicine, National AcademicPress,2011,https:// www.nal.usda.gov/sites/default/files/fnic_uploads// recommended_intakes_individuals.pdf. (accessed December 20, 2016).

[20] Singleton VL, Orthofer R, Lamuela-Raventos RM. Analysis of total phenols and other oxidation substrates and antioxidants by means of Folin-Ciocalteu reagent. Methods Enzymol. 1999; 299:152-178.

[21] Samatha T, Shyamsundarachary R, Srinivas P, Swamy NM. Quantification of total phenolic and total flavonoid contents in extracts of Oroxylum indicum L. Kurz. Asian J Pharm Clin Res. 2012; 5:177-179.

[22] Prieto P, Pineda M, Aguilar M. Spectrophotometric quantitation of antioxidant capacity through the formation of a phosphomolybdenum complex: Specific application to the determination of vitamin E. Anal Biochem. 1999; 269: 337341.

[23] Apak R, Güçlü K, Özyürek M, Karademir SE. Novel total antioxidant capacity index for dietary polyphenols and vitamins $\mathrm{C}$ and $\mathrm{E}$, using their cupric ion reducing capability in the presence of neocuproine: CUPRAC method. J Agric Food Chem. 2004; 52:7970-7981.

[24] Jayaprakasha GK, Jaganmohan RL, Sakariah KK. Antioxidant activities of flavidin in different in vitro model systems. Bioorg Med Chem. 2004; 12(19):5141-5146.

[25] Altundag H, Bina E, Altıntıg E. The levels of trace elements in honey and molasses samples that were determined by ICPOES after microwave digestion method. Biol Trace Elem Res. 2016; 170: 508-514. 